\title{
High dose nitroglycerin treatment in a patient with cardiac arrest: a case report
}

\author{
Maya Guglin* and Gilbert Postler
}

Address: Department of Cardiology, University of South Florida, 2 Tampa General Circle, Tampa, FL 33606, USA

Email: MG* - mguglin@health.usf.edu; GP - gpostler@health.usf.edu

* Corresponding author

Received: II January 2009 Accepted: 24 March 2009 Published: 10 August 2009

Journal of Medical Case Reports 2009, 3:8782 doi: 10.4076/1752-1947-3-8782

This article is available from: http://jmedicalcasereports.com/jmedicalcasereports/article/view/8782

(c) 2009 Guglin and Postler; licensee Cases Network Ltd.

This is an Open Access article distributed under the terms of the Creative Commons Attribution License (http://creativecommons.org/licenses/by/3.0),

which permits unrestricted use, distribution, and reproduction in any medium, provided the original work is properly cited.

\begin{abstract}
Introduction: Vasodilators like nitroglycerin or nitroprusside improve hemodynamics in patients with advanced heart failure. However, using these agents in critical conditions is limited because of their ability to decrease systemic blood pressure.

Case presentation: We report the rapid effect of high dose intravenous nitroglycerin treatment in an 86-year-old man after cardiac arrest and prolonged resuscitation, together with previous observations and a brief review of the literature.
\end{abstract}

Conclusion: High dose intravenous nitroglycerin can be beneficial in cardiac arrest.

\section{Introduction}

Vasodilators like nitroglycerin (NTG) or nitroprusside improve hemodynamics in patients with advanced heart failure (HF). However, using these agents in critical conditions is limited because of their ability to decrease systemic blood pressure (BP). We report a case of successful use of high-dose intravenous NTG in a patient after cardiac arrest.

\section{Case presentation}

An 86-year-old Caucasian man with a history of coronary artery disease, coronary artery bypass surgery in 1999, hyperlipidemia and hypertension, came to the out-patient laboratory of the hospital to check the results of his blood tests. His home medications included $40 \mathrm{mg}$ daily of lisinopril, $40 \mathrm{mg}$ daily of furosemide, and $80 \mathrm{mg}$ daily of simvastatin. He complained of sudden pressure-like chest discomfort and collapsed in the waiting area. The "code blue" emergency call was given. The team responding to the call applied an automated external defibrillator and delivered a shock. The recorded rhythm indicated ventricular tachycardia. Consequently, the patient was given $300 \mathrm{mg}$ of amiodarone, which resulted in the restoration of his normal sinus rhythm. The ventricular tachycardia was immediately restarted. For the next 16 minutes, ventricular tachycardia and ventricular fibrillation were treated with additional shocks and multiple doses of epinephrine, amiodarone and lidocaine.

After 16 minutes of resuscitation, the patient's normal sinus rhythm was restored, and he was transferred to the medical intensive care unit, intubated and started on mechanical ventilation. He was unconscious, and his BP was 98/58. The laboratory tests drawn at this time 
showed his white blood cells at $16.6 \mathrm{G} / \mathrm{L}$, hemoglobin $10.2 \mathrm{G} / \mathrm{dL}$ and platelets $175 \mathrm{G} / \mathrm{L}$. His coagulation test results and chemistry were normal.

After 15 minutes of normal rhythm, the patient again developed ventricular tachycardia. Following the advanced cardiac life support protocol, resuscitation efforts continued for 50 more minutes, using epinephrine, vasopressin, amiodarone, lidocaine, magnesium and bicarbonate. Eventually, the monitor recorded asystole and the patient had no spontaneous respirations, pulse, $\mathrm{BP}$, or heart sounds. Based on previous experience with a patient, we gave him $4 \mathrm{mg}$ of NTG intravenously as a bolus as a last resort. After three minutes of chest compressions the patient was pronounced dead and all resuscitative efforts were stopped.

Two minutes later, however, the nurse discovered that the patient was breathing, in normal sinus rhythm, with a palpable pulse, and a BP of 137/58 $\mathrm{mmHg}$. The ventilator was turned back on, and the patient was treated with NTG, heparin, amiodarone drips and aspirin.

The next morning, the patient's troponin I level was elevated at $23.9 \mathrm{ng} / \mathrm{mL}$ (upper normal limit 0.05), which is consistent with acute myocardial infarction (MI). His electrocardiogram displayed normal sinus rhythm and his left bundle branch block was the same as pre-event recordings. His chest X-ray was negative. He was extubated on the second hospital day, with his mental status gradually returning to his baseline. His BP remained stable at $120-150 \mathrm{mmHg}$ systolic. An echo displayed a reduced ejection fraction of $30 \%$ with global hypokinesis and an akinetic inferior wall. An adenosine-sestamibi stress test displayed areas of infarction of the inferolateral and anterolateral walls with a small area of reversibility. Taking his advanced age into account, we decided against performing cardiac catheterization. He subsequently underwent implantation of an automated defibrillator and was discharged from the hospital on day 18 .

\section{Discussion}

Only one known similar case has been previously reported in the English language literature. In 1984, Ward and Reid [1] described a 64-year-old woman with an acute MI who had a cardiac arrest. She had ventricular tachycardia and was cardioverted to sinus bradycardia, intubated and ventilated. She received atropine, epinephrine, and calcium chloride, and had pericardiocentesis and rapid saline infusions. However, she still did not have a detectable BP. She was then started on NTG at $1 \mathrm{mg} /$ minute. In three minutes, her BP was $80 / 60 \mathrm{mmHg}$. Several days later, her cardiac catheterization demonstrated severe coronary artery disease and a large anteroapical and septal infarction with aneurysm formation. She was eventually discharged from the hospital.

In 1990 [2], and in 1997 [3], we reported a case series in which the infusion of high doses of NTG resulted in rapid improvement in some patients with cardiogenic shock due to acute MI or advanced heart failure. The results are summarized in Table 1.

High doses of NTG were used in 22 patients, including 14 patients with acute MI and eight patients with advanced HF. All patients had critically low BP measured by cuff, and 18 had an unmeasurable BP and pulse. They all had cold and mottled skin and increased central venous pressure. Eleven patients had rales in the lungs, three had pulmonary edema, and one had anasarca. The doses of NTG used in each patient, as well as the times of infusions, are listed in Table 1. BP became obtainable or increased in 20 of 22 patients immediately after intravenous NTG was administered. In the end, 13 patients survived.

We recently presented these data to a group of cardiology fellows, one of whom administered the bolus of NTG to our patient in this case.

According to current recommendations, intravenous NTG is contraindicated if systolic BP is below $90 \mathrm{mmHg}$. Hemodynamic properties of vasodilators, and of nitrates in particular, were extensively studied in the 1970s and 1980s, although usually not in terminal patients with no BP. In 1972, Franciosa et al. [4] reported that intravenous sodium nitroprusside increased cardiac output and decreased wedge pressure in 15 patients with acute MI and elevated left ventricular filling pressure. Their BP was not allowed to fall below $95 \mathrm{mmHg}$, with the average drop in systolic BP at only $26 \mathrm{mmHg}$. Similar results were achieved in severe HF secondary to ischemic or dilated cardiomyopathy [5].

In 1975, Chatterjee et al. [6] described a beneficial effect of nitroprusside in 43 patients with acute MI and severe pump failure. In their series, the cardiac index increased from 1.7 to $2.2 \mathrm{~L} / \mathrm{min} / \mathrm{m}^{2}$, while the left ventricular filling pressure decreased by $35 \%$. The mean arterial pressure decreased from $83 \pm 1.5$ to $73 \pm 1.7 \mathrm{mmHg}$. Although these patients had BP of $\leq 90 \mathrm{~mm} \mathrm{Hg}$ by cuff, only 17 had clinical shock syndrome.

In another study evaluating incremental doses of intravenous NTG in patients with left ventricular failure the maximal hemodynamic benefit, in terms of decrease in wedge pressure and increase in cardiac index, was obtained at $160 \mathrm{mcg} / \mathrm{min}$, which represented the highest dose tested [7]. 
Table I. BP Response and Clinical Outcomes after High Dose NTG

\begin{tabular}{|c|c|c|c|c|c|c|c|}
\hline \multirow[t]{2}{*}{ S. No } & \multirow[t]{2}{*}{ Sex } & \multirow[t]{2}{*}{ Age } & \multicolumn{2}{|c|}{$\mathrm{BP}, \mathrm{mm} \mathrm{Hg}$} & \multirow[t]{2}{*}{ NTG, m } & \multirow[t]{2}{*}{ Time, $\min$} & \multirow[t]{2}{*}{ Outcome } \\
\hline & & & Before NTG & After NTG & & & \\
\hline I & $\mathrm{m}$ & 59 & 0 & $80 / 60$ & 20 & 30 & died \\
\hline 2 & $f$ & 77 & 0 & 0 & 5 & 5 & died \\
\hline 3 & $\mathrm{~m}$ & 60 & 0 & 0 & 15 & 10 & died \\
\hline 4 & f & 62 & 0 & $40 / 30$ & 48 & 20 & died \\
\hline 5 & $f$ & 63 & 0 & $40 / 30$ & 10 & I & died \\
\hline 6 & f & 63 & 0 & $140 / 90$ & 10 & 5 & died \\
\hline 7 & $\mathrm{~m}$ & 43 & 0 & $80 / 70$ & 6 & 2 & died \\
\hline 8 & $\mathrm{~m}$ & 68 & 0 & $80 / 60$ & 15 & 10 & died \\
\hline 9 & $\mathrm{~m}$ & 63 & 0 & $80 / 60$ & 20 & 10 & died \\
\hline 10 & $\mathrm{~m}$ & 54 & 0 & $80 / 60$ & 10 & 10 & survived \\
\hline II & $f$ & 71 & 0 & $90 / 70$ & 35 & 15 & survived \\
\hline 12 & $f$ & 65 & $80 / 70$ & $100 / 80$ & 15 & 10 & survived \\
\hline 13 & $\mathrm{~m}$ & 78 & 0 & $120 / 80$ & 48 & 15 & survived \\
\hline 14 & $\mathrm{~m}$ & 62 & 0 & $140 / 80$ & 40 & 10 & survived \\
\hline 15 & $\mathrm{~m}$ & 60 & 0 & $90 / 70$ & 25 & 3 & survived \\
\hline 16 & $f$ & 52 & $60 / 50$ & $80 / 60$ & 15 & 10 & survived \\
\hline 17 & $f$ & 64 & 0 & $120 / 80$ & 5 & 1 & survived \\
\hline 18 & $\mathrm{~m}$ & 64 & 0 & $80 / 60$ & 40 & 5 & survived \\
\hline 19 & $\mathrm{~m}$ & 57 & $80 / 60$ & $100 / 60$ & 1 & 50 & survived \\
\hline 20 & $\mathrm{~m}$ & 67 & $60 / 40$ & $110 / 70$ & 10 & 2 & survived \\
\hline 21 & $\mathrm{~m}$ & 67 & 0 & $100 / 60$ & 30 & 5 & survived \\
\hline 22 & $\mathrm{~m}$ & 47 & 0 & $80 / 60$ & 25 & 10 & survived \\
\hline
\end{tabular}

Stevenson et al. [8] found that after-load reduction with nitroprusside in severe HF leads to smaller left ventricular end-diastolic volume and less severe mitral regurgitation, resulting in greater forward flow. The BP cutoff for nitroprusside infusion was $80 \mathrm{mmHg}$. In the emergency department, boluses of intravenous NTG ranging from $0.05 \mathrm{mg}$ to $0.4 \mathrm{mg}$ repeated every five minutes as needed for chest pain were used successfully to treat ischemia due to MI or unstable angina. Systolic BP was not allowed to drop below $95 \mathrm{mmHg}$ [9].

Recently, there has been increased interest in high dose intravenous nitrates. Cotter et al. [10] randomized patients with pulmonary edema into cohorts receiving isosorbide dinitrate at $3 \mathrm{mg}$ bolus administered intravenously every five minutes versus traditional treatment using low doses of isosorbide, furosemide, and morphine. BP was not allowed to be $<90 \mathrm{mmHg}$. Mechanical ventilation was required in $13 \%$ of the high dose nitrates group and in $40 \%$ of the traditional group. MI occurred in $17 \%$ and 37\%, respectively. Similar results were obtained by Phillip Levy et al. [11], who administered up to 10 doses of NTG in intravenous boluses of $2 \mathrm{mg}$ every three minutes to treat pulmonary edema with hypertension (systolic $\mathrm{BP}>160 \mathrm{mmHg}$ ). In comparison with historical controls, fewer intubations, MIs, and intensive care unit admissions occurred.

One animal study has demonstrated the benefits of NTG in pigs after prolonged resuscitation. After four minutes of ventricular fibrillation and four minutes of standard CPR, pigs were randomized to the combination of epinephrine, vasopressin and NTG $(7.5 \mathrm{mcg} / \mathrm{kg})$ versus epinephrine alone. The mean coronary perfusion pressures, left ventricular, and global cerebral blood flow were significantly higher in animals who received NTG as part of the therapy. Spontaneous circulation was restored in 11 of 12 animals in the NTG group, versus 6 of 12 swine after epinephrine alone $(P=N S)$ [12].

A possible explanation for the hemodynamic benefit of NTG in our patients is increased cardiac output produced by rapid vasodilatation in a heart operating at the extreme of the Frank-Starling curve. Vasodilators in heart failure with or without acute myocardial infarction have been proven to decrease left ventricular filling pressure and systemic vascular resistance while increasing cardiac index [7]. The more severe the failure, the more beneficial the effect of vasodilators [13].

Interventricular dependence can also be a factor in cases where elevation of right ventricular pressure compromising filling of the left ventricle occurs due to severe congestion resulting from pre-existing systolic dysfunction and precipitated by ongoing ischemia. In this case, decreased preload after NTG can improve left ventricular filling and further increase cardiac output [14].

\section{Conclusions}

In summary, we have presented a case where high dose NTG in cardiac arrest causes dramatic effects on a patient. Further investigations are needed. In particular, such 
treatment could be tested during the resuscitation of cardiac patients after the exhaustion and failure of current protocols.

\section{Abbreviations}

ACLS, advanced cardiac life support; BP, blood pressure; $\mathrm{CPR}$, cardio-pulmonary resuscitation; $\mathrm{MI}$, myocardial infarction; NTG, nitroglycerin.

\section{Competing interests}

The authors declare that they have no competing interests.

\section{Consent}

Written informed consent was obtained from the patient for publication of this case report and any accompanying images. A copy of the written consent is available for review by the Editor-in-Chief of this journal.

\section{Authors' contributions}

MG described her past experience with high dose NTG at the fellows conference. GP who was at this conference used it on a dying patient and successfully resuscitated him. GP described the case, MG edited it and wrote the literature review and contributed her old data. Both read and approved the final manuscript.

\section{References}

I. Ward WG, Reid RL: High-dose intravenous nitroglycerin during cardiopulmonary resuscitation for refractory cardiac arrest. Am J Cardiol 1984, 53:1725.

2. Guglina ME: [Intravenous jet administration of nitroglycerin in cardiogenic shock]. Klin Med (Mosk) 1990, 68:56-58.

3. Guglina ME: High-dose nitroglycerin in cardiogenic shock. Klin Med [Mosk] 1997, 75:27-30.

4. Franciosa JA, Limas CJ, Guiha NH, Rodriguera E, Cohn JN: Improved left ventricular function during nitroprusside infusion in acute myocardial infarction. Lancet 1972, 1:650-654.

5. Guiha NH, Cohn JN, Mikulic E, Franciosa JA, Limas CJ: Treatment of refractory heart failure with infusion of nitroprusside. N Engl J Med 1974, 291:587-592.

6. Chatterjee K, Swan HJ, Kaushik VS, Jobin G, Magnusson P, Forrester JS: Effects of vasodilator therapy for severe pump failure in acute myocardial infarction on short-term and late prognosis. Circulation 1976, 53:797-802.

7. Bayley S, Valentine H, Bennett ED: The haemodynamic responses to incremental doses of intravenous nitroglycerin in left ventricular failure. Intensive Care Med 1984, I0:139-145.

8. Stevenson LW, Bellil D, Grover-McKay M, Brunken RC, Schwaiger M, Tillisch JH, Schelbert HR: Effects of afterload reduction (diuretics and vasodilators) on left ventricular volume and mitral regurgitation in severe congestive heart failure secondary to ischemic or idiopathic dilated cardiomyopathy. Am J Cardiol 1987, 60:654-658.

9. Nashed AH, Allegra JR, Larsen S, Horowitz M: Bolus i.v. nitroglycerin treatment of ischemic chest pain in the ED. Am J Emerg Med 1994, I 2:288-29|.

10. Cotter G, Metzkor E, Kaluski E, Faigenberg Z, Miller R, Simovitz A, Shaham O, Marghitay D, Koren M, Blatt A, Moshkovitz Y, Zaidenstein R, Golik A: Randomised trial of high-dose isosorbide dinitrate plus low-dose furosemide versus high-dose furosemide plus low-dose isosorbide dinitrate in severe pulmonary oedema. Lancet 1998, 35 I:389-393.

II. Levy P, Compton S, Welch R, Delgado G, Jennett A, Penugonda N, Dunne R, Zalenski R: Treatment of Severe Decompensated Heart Failure With High-Dose Intravenous Nitroglycerin: A
Feasibility and Outcome Analysis. Ann Emerg Med 2007, 50:144-152. (Epub May 23, 2007).

12. Lurie KG, Voelckel WG, Iskos DN et al.: Combination drug therapy with vasopressin, adrenaline (epinephrine) and nitroglycerin improves vital organ blood flow in a porcine model of ventricular fibrillation. Resuscitation 2002, 54:187-194.

13. Flaherty JT: Comparison of intravenous NTG and sodium nitroprusside in acute MI. Am J Med 1983, 74:53-60.

14. Frenneaux M, Williams L: Ventricular-arterial and ventricularventricular interactions and their relevance to diastolic filling. Prog Cardiovasc Dis 2007, 49:252-262.

\section{Do you have a case to share?}

Submit your case report today

- Rapid peer review

- Fast publication

- PubMed indexing

- Inclusion in Cases Database

\section{Any patient, any case, can teach us something}

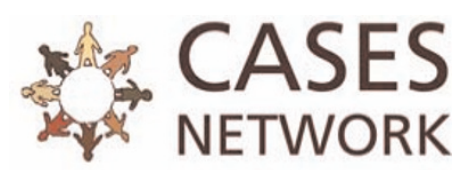

www.casesnetwork.com 